\title{
Caracterização de danos e resistência residual de um laminado híbrido metal/fibra após impactos repetidos de baixa energia
}

\author{
TARPANI, J.R.; CARDOSO, F.L.A.; GUALBERTO, A.R.M.; GATTI M.C.A. \\ Escola de Engenharia de São Carlos-EESC/USP, Departamento de Engenharia de Materiais, \\ Avenida Trabalhador São-Carlense, 400, CEP 13566-590, São Carlos-SP, Brasil \\ e-mails: jrpan@sc.usp.br ; felipecardoso@usp.br ; gualberto@sc.usp.br ; mcgatti@sc.usp.br
}

\begin{abstract}
RESUMO
A energia absorvida pelo laminado metal/fibra Glare ${ }^{\circledR}$ durante impactos repetidos de baixa energia aplicados segundo três diferentes sequências de carregamento dinâmico foi determinada através de um aparato Laser-Doppler. Os resultados indicaram que a energia absorvida $\left(E_{a}\right)$ foi cerca de $40 \%$ da energia total disponibilizada $\left(E_{t}=6\right.$ Joules), independentemente da sequência de impactos empregada. As propriedades mecânicas residuais do laminado em condições de flexão monotônica sob três pontos, assim como os danos visualmente detectáveis criados por impacto no material, também não revelaram efeitos significativos da história de cargas dinâmicas experimentada pelo laminado híbrido.
\end{abstract}

Palavras-chave: Laminado metal/fibra, impacto repetido, tolerância a danos.

\section{Damage characterization and residual resistance of fiber/metal laminate after low energy repeated impact}

\section{ABSTRACT}

The energy absorbed by the fiber/metal laminate Glare ${ }^{\mathrm{TM}}$ during low-energy repeated impact events according to three different dynamic loading sequences has been determined using a Laser-Doppler apparatus. The results indicated that the absorbed energy $\left(\mathrm{E}_{\mathrm{a}}\right)$ was approximately $40 \%$ of the total available energy $\left(E_{t}=6\right.$ Joules) regardless of the impact sequence applied. The residual mechanical properties of the laminate under three-point flexural conditions, as well as the visually detectable damage created by impact on the material, did not show any significant effect of the dynamic loading sequence withstood by the hybrid laminate.

Keywords: Damage tolerance, fiber/metal laminate, repeated impact.

\section{INTRODUÇÃO}

Glare $^{\circledR}$ (Glass-Reinforced Aluminum Laminate) é o laminado híbrido da classe dos metal/fibra (LMF) mais conhecido e empregado na indústria aeronáutica. Ele combina as atrativas características dos metais, como, por exemplo, boa resistência ao impacto e ótima conformabilidade, com as melhores propriedades dos materiais compósitos fortalecidos com fibras contínuas, como elevada resistência à fadiga associada a um baixo peso [1,2].

O emprego de Glare em componentes aeronáuticos externos, tais como fuselagens e bordos de ataque, assim como internos, tais como soalhos e revestimentos, requer o conhecimento de seu desempenho sob condições de carregamento sob impactos repetidos de baixa energia, aos quais se expõem aquelas partes do veículo em condições normais de operação e serviço. Por exemplo, é bem conhecida a questão dos fragmentos da pista lançados contra a superfície externa da aeronave pelo atrito dos pneus com o solo durante pousos e decolagens [3,4]. A questão do contato repetido de saltos agudos de sapato contra o soalho de aeronaves, a despeito da proteção exercida pelo carpete que geralmente o recobre, é também preocupante, visto que, em algumas aeronaves, este componente é considerado primário, ou seja, de extrema responsabilidade, já que, assim como a fuselagem e as paredes de pressão, ele suporta a pressurização interna do veículo [5]. Apenas como exemplo, uma mulher pesando $65 \mathrm{~kg}$ e andando de salto alto exerce uma 
pressão da ordem de $140 \mathrm{~kg} / \mathrm{cm}^{2}$, que pode chegar a $560 \mathrm{~kg} / \mathrm{cm}^{2}$ no caso do uso de saltos agulha (http://www.woodfloors.org/consumer/maintReg.aspx). Este tipo de impacto é provavelmente suficiente para endentar qualquer piso laminado compósito. Desta forma, a habilidade de um material resistir à fadiga por impacto é uma característica importante que deve ser considerada quando materiais são selecionados para aplicações estruturais em engenharia []].

A necessidade de se avaliar o comportamento de longos períodos dos laminados compósitos, visto que danos internos gerados por eventos repetidos e acumulados ao longo do tempo podem levar à falha do componente aparentemente íntegro, tem sido enfatizada [7]. Esta linha de raciocínio está intimamente vinculada ao conceito de danos de difícil visualização (BVID - Barely Visible Impact Damage [8]), segundo o qual os danos causados por impacto abaixo de uma determinada energia limite, embora improváveis de serem detectados durante inspeções rotineiras da aeronave, podem reduzir significativamente a resistência residual da estrutura. A subsequente aplicação de cargas de fadiga, inevitáveis em uma aeronave em serviço, pode, em adição, gradativamente comprometer ainda mais a integridade estrutural através do crescimento do dano previamente criado por impacto, agravando sobremaneira a possibilidade de uma falha catastrófica em vôo [9]].

A similaridade de algumas consequências do impacto nos laminados metal/fibra e em laminados compósitos convencionais tem sido verificada [1] , porém com a vantagem de que a endentação (massa) formada na camada metálica externa do material híbrido favorece a rápida inspeção visual do componente [2], reduzindo os custos de manutenção e atraindo a atenção das empresas de frotas aéreas comerciais. Neste sentido, tem sido destacada [11] a relevância de se desenvolverem materiais estruturais aeronáuticos de alto desempenho com base não apenas e tão somente em critérios de durabilidade, tolerância a danos e de manufatura, mas também pela consideração de seus custos operacionais (inspeção e manutenção), prioritários para os operadores de aeronaves [12].

No presente trabalho, o laminado híbrido metal/fibra Glare é submetido, respectivamente, a três diferentes ciclos de carregamento de impactos múltiplos de baixa energia, sendo avaliados aspectos tais como: a energia consumida nas diversas sequências de eventos dinâmicos, os danos externamente criados no material nestas ocasiões, e, finalmente, as suas propriedades residuais em flexão lenta sob três pontos. Objetiva-se, desta forma, uma melhor apreciação do desempenho desta importante classe de materiais de construção aeronáutica sob condições simulando potenciais ocorrências em serviço.

Cabe ressaltar o ineditismo deste estudo no que tange ao tipo de material empregado e aos tipos de carregamento mecânicos utilizados na sua caracterização. Em toda a literatura científica, o único trabalho que se assemelha ao aqui apresentado é o recentemente publicado por Rajkumar et al [13]; entretanto, diferentemente do que é aqui exibido, aqueles autores caracterizaram as propriedades residuais de um laminado metal/fibra sob carregamento trativo.

\section{MATERIAIS E CORPOS-DE-PROVA}

\subsection{Material}

Utilizou-se neste trabalho o laminado Glare ${ }^{\circledR}$ classificação 5, fabricado em escala industrial pela empresa canadense Comtek Advanced Structures - Burlington - Ontário - Canadá, e fornecido pela Aviation Equipments - Costa Mesa - Califórnia - EUA. O laminado, esquematizado na Figura 1, é constituído por duas lâminas de liga de $\mathrm{Al}$ 2024-T3 com 0,5 mm de espessura, entre as quais são dispostas quatro mantas de tecido unidirecional de fibras de vidro de alta resistência embebidas em resina termorrígida epóxi. As mantas são justapostas alternadamente, porém mantendo uma simetria central, numa arquitetura global do tipo 2/1 $\left(0^{\circ} / 90^{\circ}\right)_{\mathrm{s}}$. A espessura total do laminado é de $1,6 \mathrm{~mm}$, com a fase metálica compondo aproximadamente $62,5 \%$ em volume do LMF. 


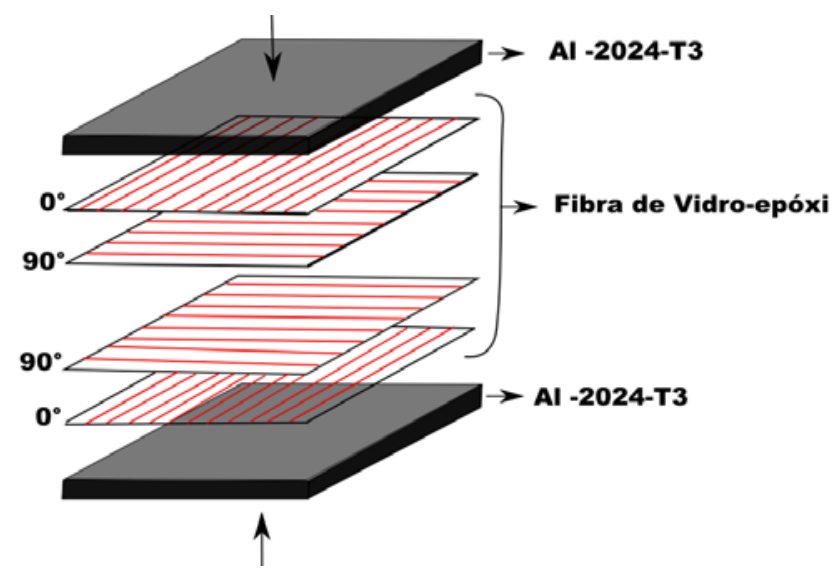

Figura 1: Disposição das diversas camadas metálicas e compósitas individuais do laminado Glare-5.

\subsection{Corpos-de-Prova}

Corpos-de-prova (CDPs) do tipo-tablete (não-normatizados), com dimensões $(65,0 \times 27,5$ x 1,6) $\mathrm{mm}^{3}$, foram usinados pela Embraer S/A. A representatividade dos ensaios de impacto transversal de espécimes compósitos convencionais com pequenas dimensões em simulações do comportamento de componentes de maior porte tem sido fartamente documentada na literatura [14-16], com a ressalva de que o dano deva se restringir a uma porção significativamente pequena dos primeiros, tal como essencialmente ocorreu neste trabalho. Dados coletados em ensaios de pequenos espécimes de LMF têm também sido empregados na previsão da resposta de estruturas mais robustas e representativas [17,18].

\section{MÉTODOS EXPERIMETAIS E ANALÍTICOS}

\subsection{Impacto Repetido por Queda-de-Peso (Drop-Weight Test)}

Nesta modalidade de ensaio de impacto, uma massa é liberada de uma altura previamente determinada e se choca perpendicularmente à face frontal do CDP. O impacto, em geral, não causa a destruição completa, ou perfuração, do material ensaiado, havendo um ricocheteio (ou rebote) do impactador. Neste trabalho, a coleta dos dados de interesse foi realizada por intermédio de um velocímetro LaserDoppler. O efeito Doppler se traduz por uma mudança na frequência aparente das ondas quando emitidas, ou refletidas por um objeto que está em movimento em relação a um observador, sendo esta mudança proporcional à velocidade do objeto. Isto permite o monitoramento da velocidade de objetos em função do tempo (vide Figura 2), através da reflexão de ondas (no caso utilizando frequências luminosas) emitidas pelo próprio equipamento de medição.

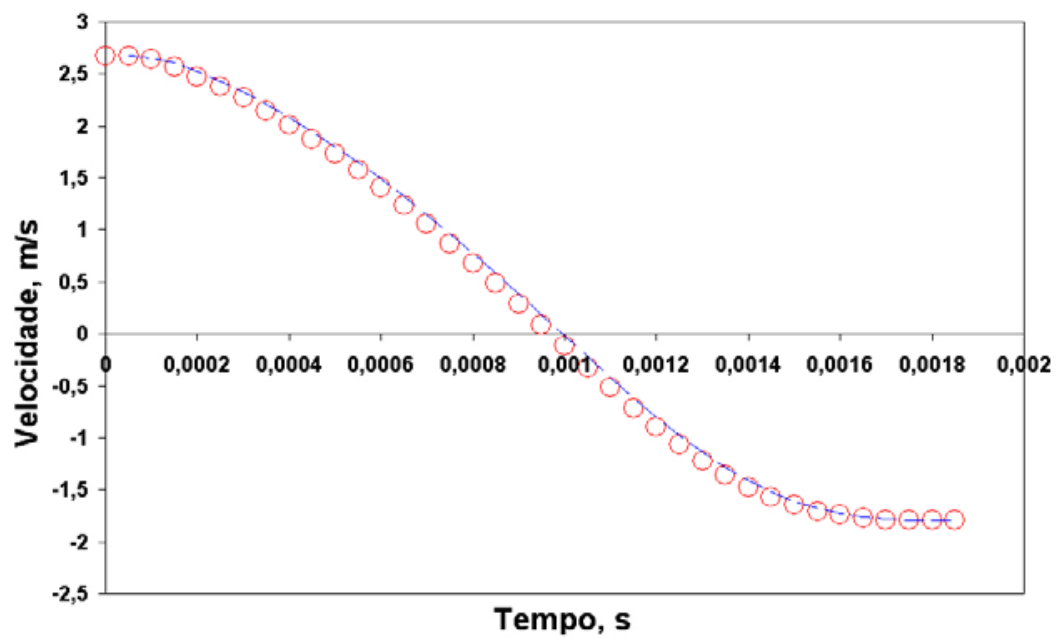

Figura 2: Exemplo de diagrama de velocidade contra o tempo fornecido pelo dispositivo Laser-Doppler, em que os extremos denotam, respectivamente, as velocidades de impacto e de rebote do projétil. 
O aparato de ensaio por queda-de-peso (drop-weight testing rig) foi construído artesanalmente, sendo mostrado esquematicamente na Figura 3. O dispositivo é simples, compacto, robusto e de baixo custo, substituindo adequadamente sistemas de impacto comerciais mais sofisticados. Para uma abordagem mais conservadora, ou seja, que compromete mais severamente as propriedades residuais de laminados compósitos impactados [19-22], utilizou-se um impactador com ponta esférica de aço com $5 \mathrm{~mm}$ de diâmetro e massa de $0,103 \mathrm{~kg}$.

Os ensaios de impacto repetido de baixa energia foram realizados segundo três diferentes séries de 10 impactos subsequentes, denominadas respectivamente CON (constante), CRE (crescente) e DEC (decrescente), dependendo dos níveis energéticos das cargas aplicadas, os quais são graficamente expressos na Figura 4.

No modo CON (Fig.4a), foram aplicados 10 impactos subsequentes de 0,6 J cada (peso liberado de uma altura de $60 \mathrm{~cm}$ ). No modo CRE (Fig.4b), os 10 impactos foram realizados com valores crescentes de energia, sendo o primeiro de $0,2 \mathrm{~J}$ (peso liberado de uma altura de $20 \mathrm{~cm}$ ) e o último de 1,0 J (peso liberado de uma altura de 1 metro), com intervalos regulares de 0,1 J. No modo DEC (Fig.4c), seguiu-se basicamente a mesma metodologia do modo CRE, porém de modo inverso, sendo o primeiro impacto de $1,0 \mathrm{~J}$ e o último de $0,2 \mathrm{~J}$.

Vale enfatizar que a somatória das energias de impacto aplicadas nos três modos avaliados foi exatamente a mesma, de 6 Joules, conforme mostra a Figura 4c de energias acumuladas.

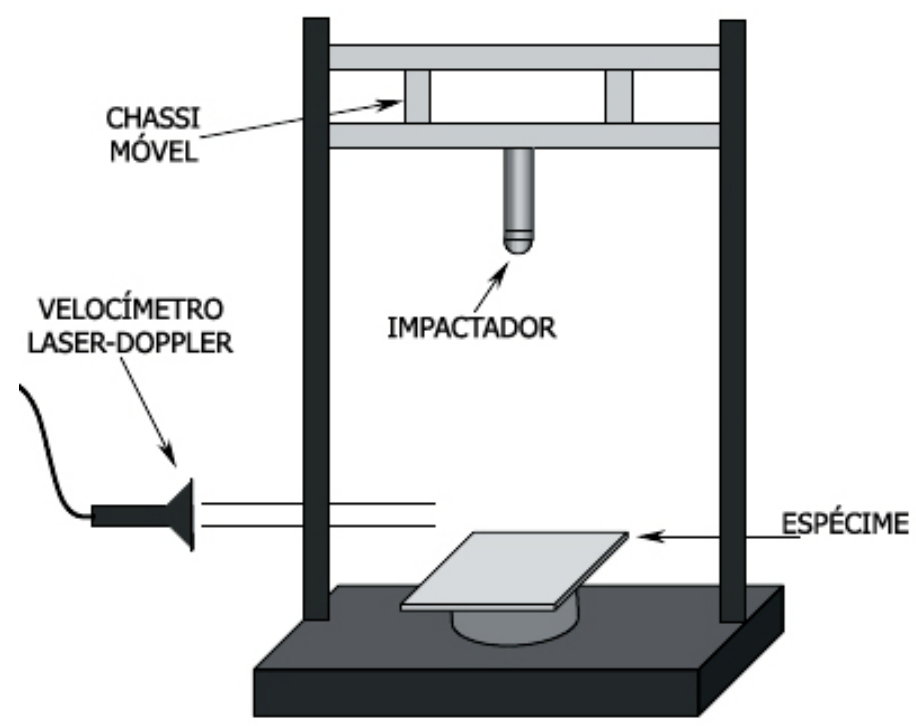

Figura 3: Esquema do aparato de ensaio por queda livre de peso empregado neste estudo [23]

\subsection{Determinação das Energias Absorvida e Recuperada no Impacto}

Diversos métodos analíticos foram previamente derivados [24] para a obtenção das energias consumida (absorvida - $E_{a}$ ) e elástica (recuperada - $E_{r}$ ) por espécimes de laminados metal/fibra submetidos a impacto único transversal com energias superiores a 1 Joule. Concluiu-se neste estudo recente que, nestas condições, o Método Laser-Doppler (LD) implica numa leve superestimativa de $\mathrm{E}_{\mathrm{a}}$, se comparado ao Método padrão da Célula de Carga (CC), devido a eventuais deslocamentos laterais experimentados pelo impactador durante o estágio de rebote, ou ricocheteio do impactador. Foi também determinado que o Método do Rebote (MR), por empregar dados obtidos pelo dispositivo Laser-Doppler, bem como por se basear em dados obtidos nos limiares dos eventos de impacto e de rebote do impactador, tende a gerar valores ainda menos conservadores que o Método LD, ainda que a estimativa de energia absorvida ocorra de modo consistente e proporcional a ambos os métodos LD e CC.

Entretanto, os resultados mostraram claramente que, para baixas energias de impacto, menores que 1 Joule, há uma clara e inequívoca tendência da convergência de estimativa de valores de energia absorvida pelo espécime segundo os três métodos, respectivamente, LD, CC e MR [24].

Desta forma, em vista da simplicidade e da rapidez de execução do Método MR, o qual é descrito na sequência do texto, e, em virtude do fato de que energias de impacto entre 0,2 e 1,0 Joules são aplicadas repetidamente no presente estudo, o que garante, com base em resultados prévios [24], a sua precisão e aplicabilidade sob tais circunstâncias, optou-se pelo seu emprego neste trabalho comparativo do efeito das variadas sequências de impacto aplicadas ao laminado híbrido Glare-5, idêntico material estrutural empregado anteriormente pelos autores [24]. 

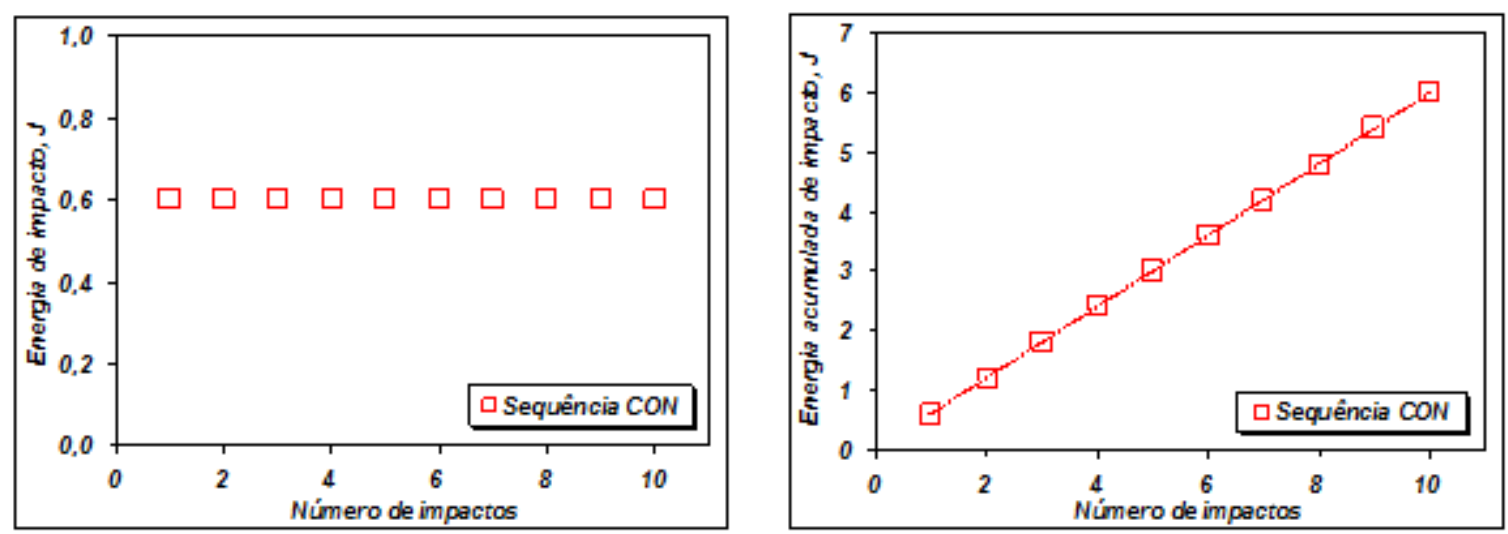

(a)
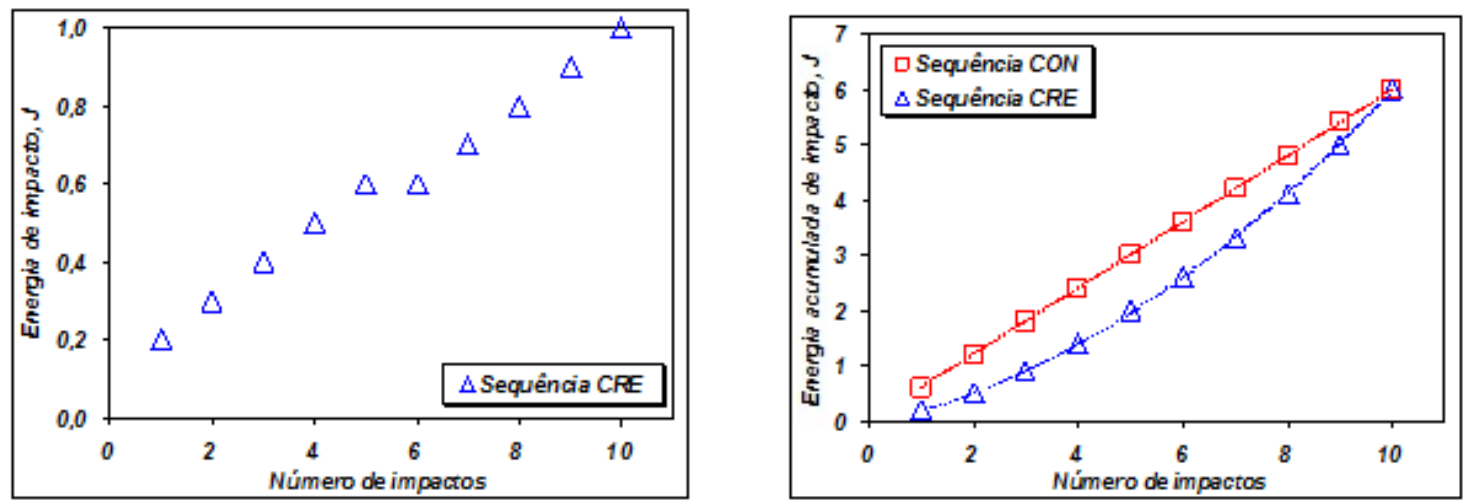

(b)
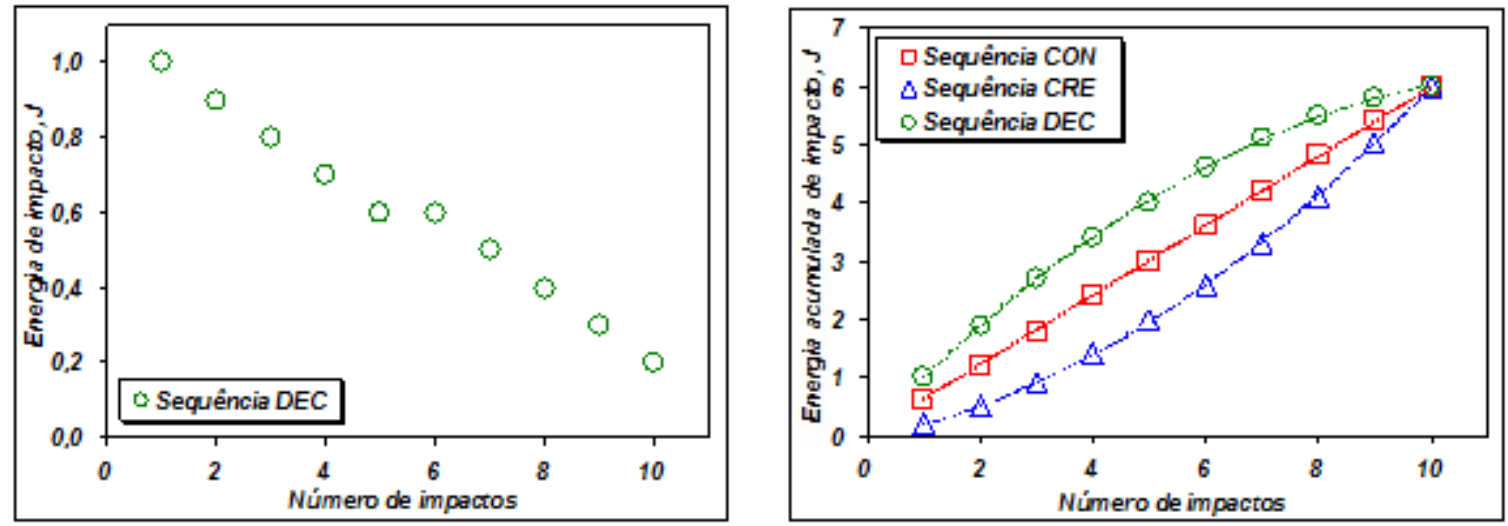

(c)

Figura 4: Sequências aplicadas nos ensaios de impacto repetido de baixa energia: (a) Modo CON (na cor vermelha); (b) Modo CRE (azul); (c) Modo DEC (verde). Os gráficos à esquerda apresentam os valores de energias aplicados individualmente em cada uma das três séries de ensaios de impactos múltiplos nos espécimes LMF, enquanto que os da direita mostram os correspondentes valores acumulados de energia.

Essencialmente, o Método MR consiste no cálculo da diferença entre a energia disponibilizada ao espécime-alvo no momento do impacto $\left(E_{\mathrm{i}}\right)$ e a energia de rebote do impactador no instante em que ele deixa de contatar o alvo $\left(E_{\mathrm{r}}\right)$, que, a rigor, é a energia recuperada (elástica) pelo material. Esta diferença é, em princípio, salvo perdas devidas a atrito e demais efeitos dissipativos externos ao CDP, a energia consumida ou absorvida $\left(E_{a}\right)$ na criação de danos no laminado impactado (Eq.1): 


$$
E_{a}=E_{i}-E_{r}
$$

Neste sentido, tanto $E_{\mathrm{i}}$ quanto $\mathrm{E}_{\mathrm{r}}$ (Eq.2) podem ser calculados por intermédio das respectivas velocidades, $\mathrm{v}_{\mathrm{i}}$ (velocidade do impactador no limiar do choque com o alvo) e $\mathrm{v}_{\mathrm{r}}$ (velocidade de rebote), as quais são precisamente estimadas pelo dispositivo Laser-Doppler, conforme exemplo provido na Figura 2.

$$
E_{r}=\frac{m \cdot v_{r}^{2}}{2}
$$

\subsection{Resistência Residual em Flexão Três Pontos (F3P)}

Visto que os danos impingidos durante os ensaios de fadiga por impacto nos espécimes de laminado Glare são de relativamente pequena monta, eles permanecem suficientemente íntegros para a determinação de sua resistência mecânica residual, que, no presente caso, é realizada através do ensaio de flexão lenta e monotônica sob três pontos (F3P).

Os ensaios F3P foram realizados em um sistema eletro-mecânico da EMIC ${ }^{\circledR}$ com fundo de escala de $10 \mathrm{kN}$, sob uma velocidade de deslocamento do travessão de $1 \mathrm{~mm} / \mathrm{min}$. A distância entre os pontos de apoio laterais foi mantida em $40 \mathrm{~mm}$, empregando-se pinos de suporte lateral e de flexão central com $8 \mathrm{~mm}$ de diâmetro. A utilização de um extensômetro axial, localizado exatamente na linha de aplicação da carga gradativa e monotonicamente imposta aos tabletes em flexão, possibilitou a obtenção de diagramas de carga vs. deslocamento, ou deflexão na linha de carga.

Estes diagramas foram posteriormente convertidos em gráficos de tensão vs. deformação, sendo ambas as quantidades (tensão e deformação) calculadas na posição de máximo esforço trativo dos espécimes, que se localiza na superfície externa do LMF, oposta àquela de contato com o pino central de aplicação da carga fletiva. Fórmulas matemáticas são providas em norma específica [드] para a determinação destas quantidades a partir de ensaios de flexão de laminados compósitos.

Os gráficos de tensão vs. deformação em flexão possibilitaram a determinação das seguintes propriedades mecânicas dos tabletes previamente impactados: resistência máxima, módulo de elasticidade e tenacidade de carga máxima. Os dois primeiros parâmetros foram determinados rigorosamente de acordo com as diretrizes estabelecidas em [25]. Neste sentido, o módulo de elasticidade foi obtido como a razão entre o intervalo de tensão e o correspondente intervalo de deformação numa faixa de deformações de 0,1 a 0,3\%. Já a tenacidade de carga máxima foi obtida pela integração da curva de tensão vs. deformação até o ponto de máxima resistência do espécime.

\section{RESULTADOS E DISCUSSÃO}

\subsection{Energias Absorvidas e Recuperadas}

\subsubsection{Modo CON de Carregamento por Impacto Repetido}

Os gráficos de barras fornecidos na Figura 5 mostram os resultados de impacto, em termos de energia absorvida $\left(E_{a}\right)$ e de sua complementar recuperada $\left(E_{r}\right)$, respectivamente a cada impacto aplicado (Fig. 5a) e acumuladas (Fig. 5b) ao longo dos 10 impactos subsequentes no modo CON. Nota-se na Figura 5a uma tendência de redução de $E_{a}$ (em termos absolutos, e, obviamente percentuais) na medida em que evolui o número de impactos sempre aplicados com uma energia constante de 0,6 J.

Segundo os resultados abaixo, a energia absorvida acumulada total, após os 10 impactos, é de 2,5 J, ou seja, de $42 \%$ da energia total disponibilizada na sequência CON de carregamento aplicado.

É interessante observar que, em linha com resultados obtidos por alguns pesquisadores em laminados compósitos reforçados respectivamente com fibras contínuas de carbono, vidro e para-aramida [26], a carga máxima alcançada durante os impactos repetidos aplicados no LMF-Glare tendeu a diminuir, a partir de certo número de impactos, na medida em que a sequência de golpes no modo CON era desenvolvida. 


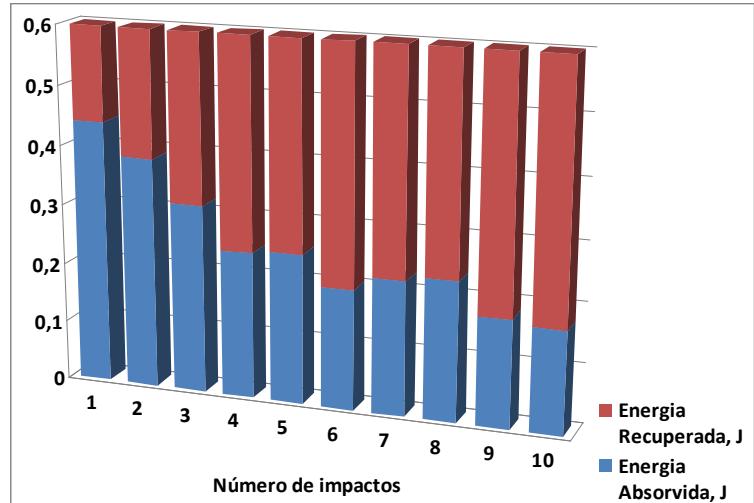

(a)

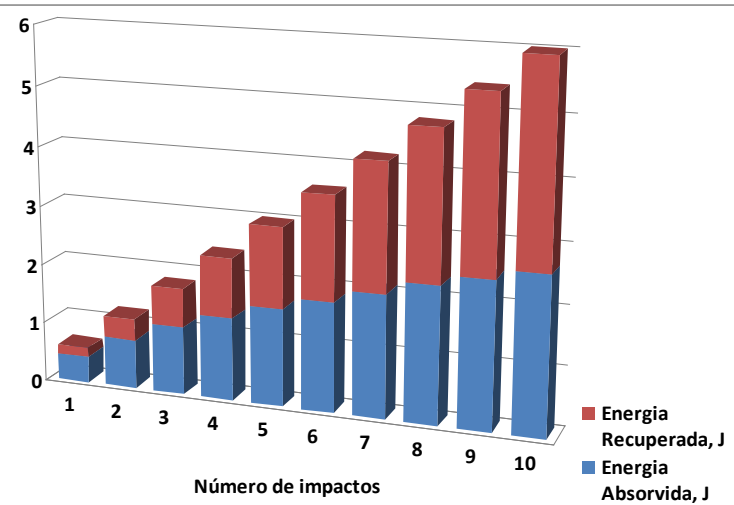

(b)

Figura 5: Gráficos de energias absorvida e recuperada na sequência de impacto repetido CON: (a) Valores individuais; (b) Acumulados.

\subsubsection{Modo CRE de Carregamento por Impacto Repetido}

Os gráficos de barras fornecidos na Figura 6 apresentam os resultados de impacto, em termos de energia $E_{a}$ e de sua complementar $E_{r}$, respectivamente a cada impacto aplicado (Fig.6a) e acumuladas (Fig.6b) ao longo dos 10 impactos subsequentes aplicados segundo o modo CRE. Nota-se na figura 6a uma clara tendência inicial de aumento da energia absorvida pelo LMF-Glare (tanto em termos absolutos, como percentualmente com relação à energia do impacto individual correspondente), para, em seguida, ocorrer uma tendência ao decréscimo destes valores na medida em que aumenta o número de impactos e a energia aplicada em cada um deles (padrão de carregamento com energia crescente entre 0,2 e $1 \mathrm{~J}$ ). Aparentemente, os resultados indicam a possibilidade da existência de um pico intermediário de capacidade de absorção de energia para este padrão de carregamento por impactos múltiplos.

Segundo os resultados abaixo, a energia absorvida acumulada é de 2,4 J, ou seja, da ordem de $40 \%$ da energia total disponibilizada nos 10 impactos segundo o padrão de carregamento CRE. Este valor é praticamente igual àquele obtido para a sequência CON de impactos múltiplos, indicando a não existência de efeitos das histórias de carregamento para o laminado Glare-5.

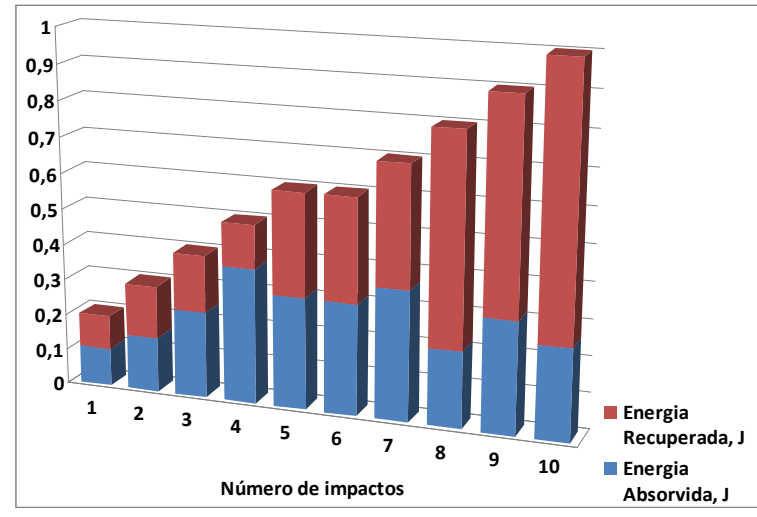

(a)

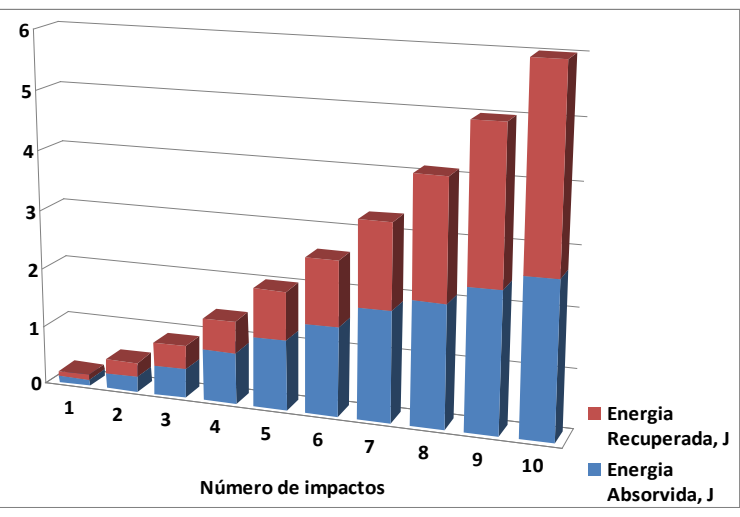

(b)

Figura 6: Gráficos de energias absorvida e recuperada na sequência de impacto repetido CRE: (a) Valores individuais; (b) Acumulados.

\subsubsection{Modo DEC de Carregamento por Impacto Repetido}

Os gráficos apresentados na Figura 7 mostram o comportamento de ambas as energias $E_{a}$ e $E_{r}$, respectivamente a cada impacto aplicado (Fig.7a) e acumuladas (Fig.7b) ao longo dos 10 impactos subsequentes no modo DEC. Nota-se na Figura 7a a tendência de redução da energia absorvida (em termos absolutos, bem como percentuais com relação à energia do impacto individual correspondente) na medida em 
que os impactos sequenciais são aplicados com uma energia sempre decrescente no intervalo de 1,0 a 0,2 J. Tal fato foi anteriormente verificado também para o modo CON de carregamento de fadiga por impacto.

Segundo os resultados abaixo, a energia absorvida acumulada é da ordem de 2,6 J, ou seja, $43 \%$ da energia total disponibilizada na sequência de 10 impactos segundo o padrão de carregamento DEC, um valor muitíssimo próximo daqueles obtidos respectivamente nas sequências CON e CRE. Isto confirma a inexistência de efeitos significativos das três histórias de carregamento por impacto no laminado Glare-5.

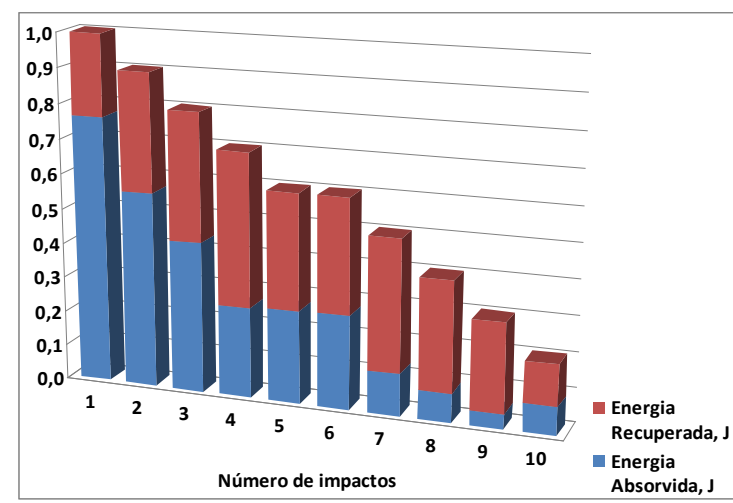

(a)

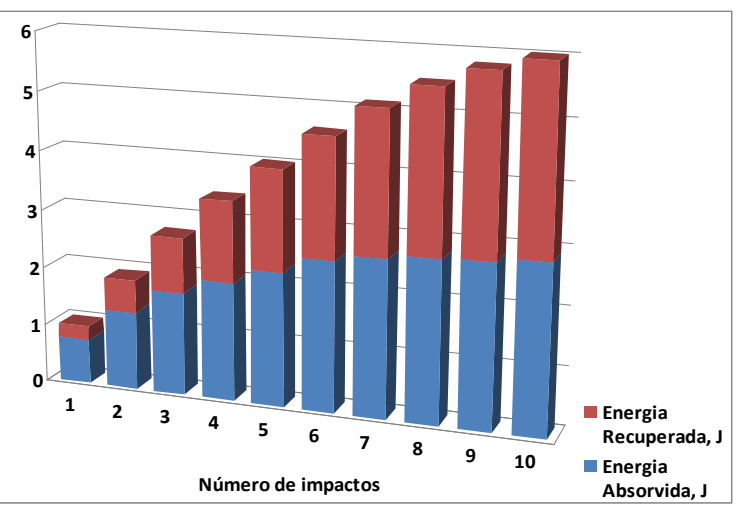

(b)

Figura 7: Gráficos de energias absorvida e recuperada na sequência de impacto repetido DEC: (a) Valores individuais; (b) Acumulados.

\subsection{Danos por Impacto}

A Figura 8 mostra, respectivamente, as faces frontal e traseira dos LMF impactados segundo as três sequências de carregamento empregadas neste estudo, sempre para uma energia total disponibilizada de $6 \mathrm{~J}$. Conclui-se que é visualmente impossível distinguir-se entre os danos externamente desenvolvidos nos laminados para os três modos de aplicação dos múltiplos impactos de baixa energia, respectivamente, CON, CRE e DEC. Este resultado concorda plenamente com o fato de as energias absorvidas acumuladas serem muito próximas entre si para estas três sequências de carregamento por impacto leve.

Para fins de comparação, a Figura 9 mostra um espécime de Glare-5 idêntico aos apresentados na Figura 8, porém com os $6 \mathrm{~J}$ de energia depositados de modo integral, pela aplicação de apenas um único impacto [24]. Torna-se claro que os danos gerados neste último caso são de muito maior monta que aqueles ilustrados na Figura 8, denotando a maior gravidade do carregamento mecânico concentrado. De fato, neste caso, o valor de energia absorvida alcançou cerca de $70 \%$ da energia de impacto, o que indica uma operacionalização mais efetiva dos mecanismos de danos no LMF.

Alguns autores [27] chamam a atenção para o fato de que a primeira falha em LMF submetidos a impacto de baixa energia ocorre na interface entre a lâmina metálica não-impactada e a lâmina compósita justaposta. Eles também verificaram que, na medida em que a energia de impacto aumenta e atinge um determinado valor limite, é forte a possibilidade do trincamento desta lâmina posterior (não-impactada).

Assim como a Figura 9, as imagens fornecidas na Figura 10 foram extraídas de trabalho recente dos autores sobre impacto em Glare-5 [24] e mostram o desenvolvimento de uma trinca na face metálica posterior de um espécime após impacto único de $6 \mathrm{~J}$. Este trincamento não foi observado pelos pesquisadores para níveis de energia inferiores, indicando, de acordo com [27], que a energia limite de trincamento por impacto do Glare-5 é da ordem de $6 \mathrm{~J}$.

No presente trabalho, esta condição limite para a geração de trinca na lâmina metálica posterior não foi alcançada em quaisquer dos casos avaliados de fadiga por impacto. Tal fato corrobora, portanto, a maior gravidade da aplicação do carregamento dinâmico concentrado de $6 \mathrm{~J}$, se comparada ao emprego de impactos múltiplos cuja somatória de energias é daquela ordem. 

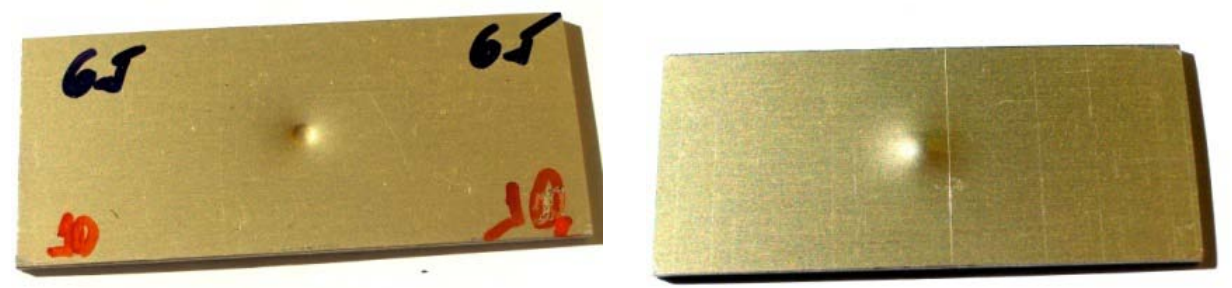

(a)
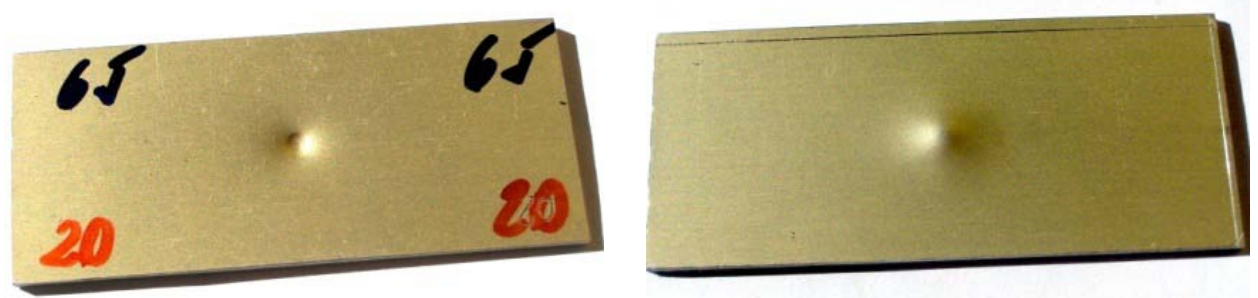

(b)
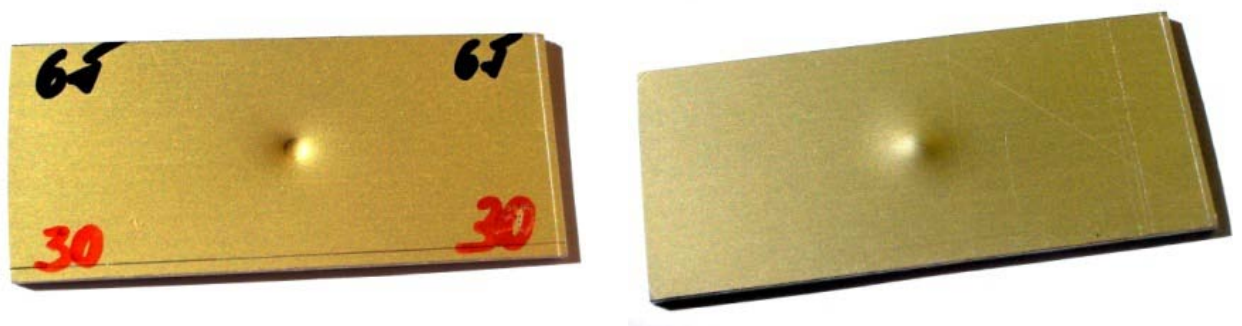

(c)

Figura 8: Respectivamente, faces frontal e traseira dos LMF impactados repetidamente segundo os modos: (a) CON; (b) CRE; (c) DEC, para uma energia acumulada de impacto de $6 \mathrm{~J}$.

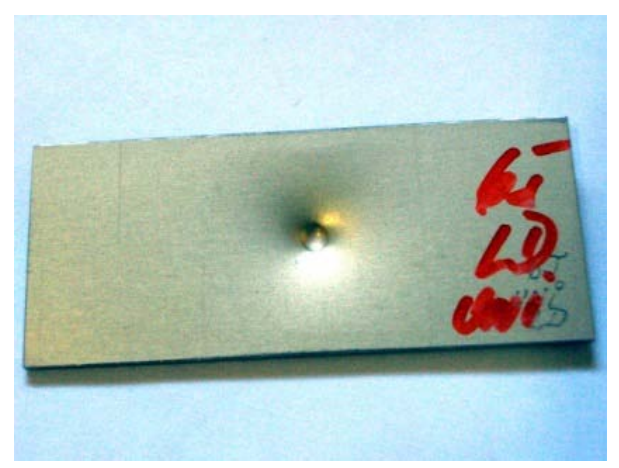

(a)

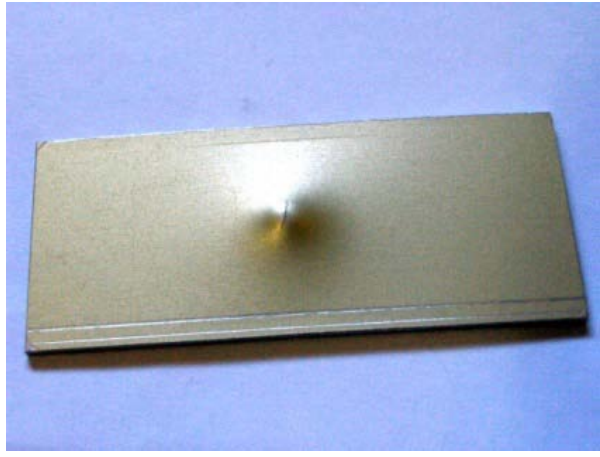

(b)

Figura 9: Respectivamente, faces frontal (a) e traseira (b) de um LMF danificado com um único impacto com energia de $6 \mathrm{~J}$ [24]. 

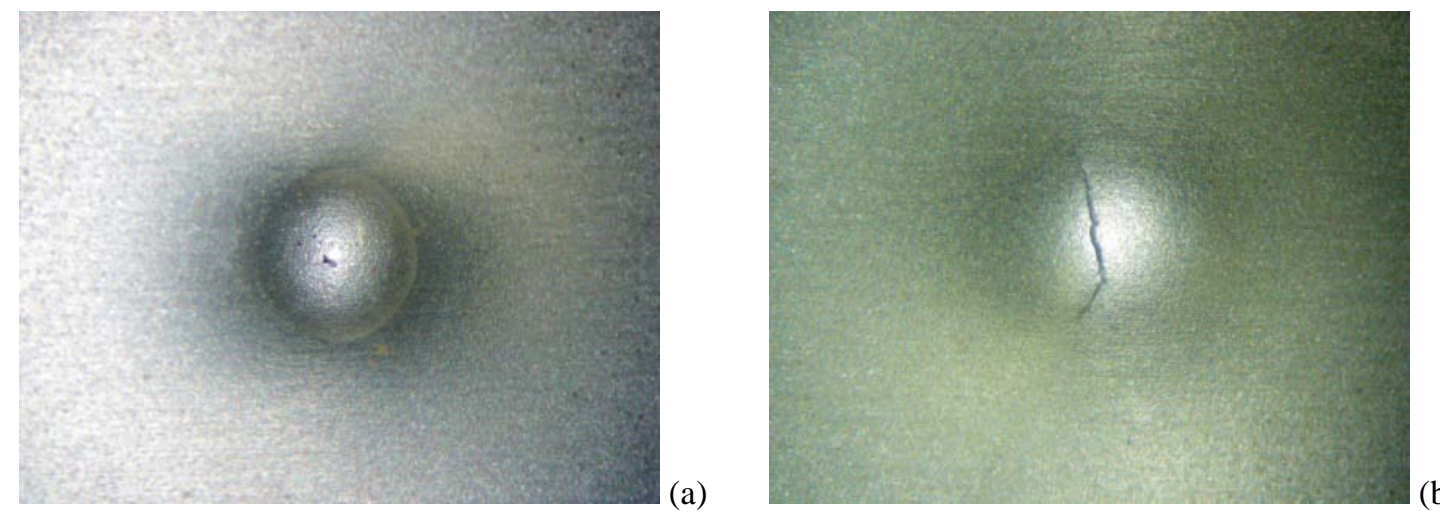

(b)

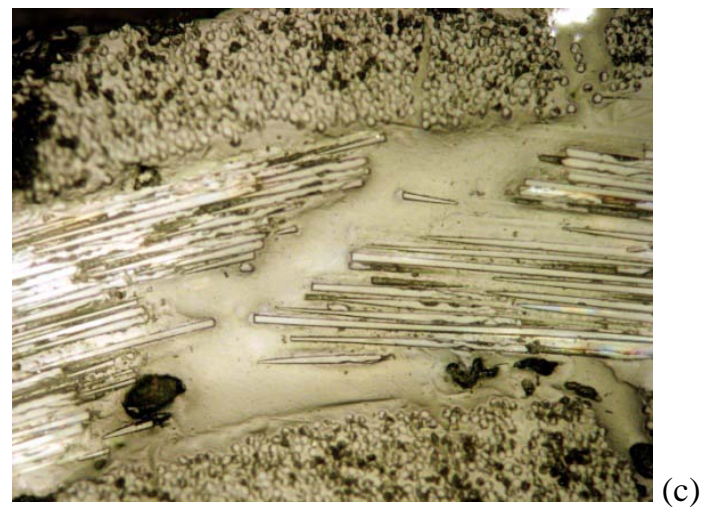

Figura 10: Detalhamento das faces frontal/impactada (a), e traseira/não-impactada (b), respectivamente, do LMF-Glare-5 danificado com um único impacto com energia de $6 \mathrm{~J}$ mostrado anteriormente na Fig.9; (c)

Vista microscópica das fibras de vidro rompidas no interior do laminado [24].

\subsection{Resistência Residual em Flexão (F3P)}

A resistência mecânica residual em F3P do LMF Glare-5 após a aplicação das sequências de impacto respectivamente denominadas CON, CRE e DEC (para uma energia acumulada de $6 \mathrm{~J}$ ), é fornecida na Figura 11. Para fins de comparação, são apresentados os resultados obtidos para o Glare-5 na condição virgem, bem como após um único impacto com energia concentrada de $6 \mathrm{~J}$ [24].

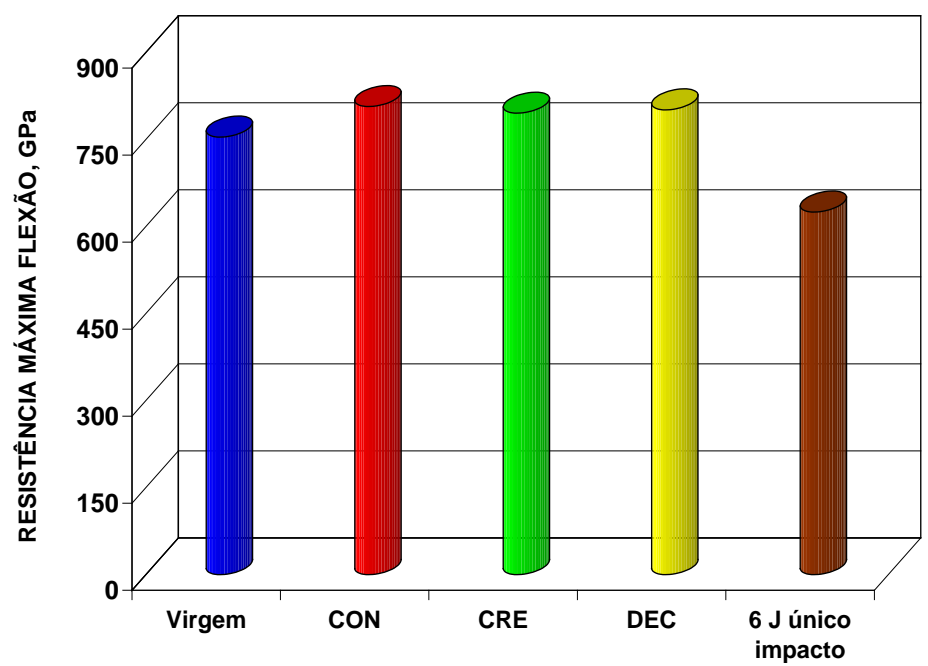

Figura 11: Desempenho do laminado metal/fibra Glare-5 em termos de resistência máxima à flexão, após diversas condições de impacto repetido (CON, CRE, DEC). A resistência residual do material nas condições virgem e após único impacto de $6 \mathrm{~J}$ [24] são também plotadas para fins de comparação. Valores médios de três ensaios para cada condição avaliada. 


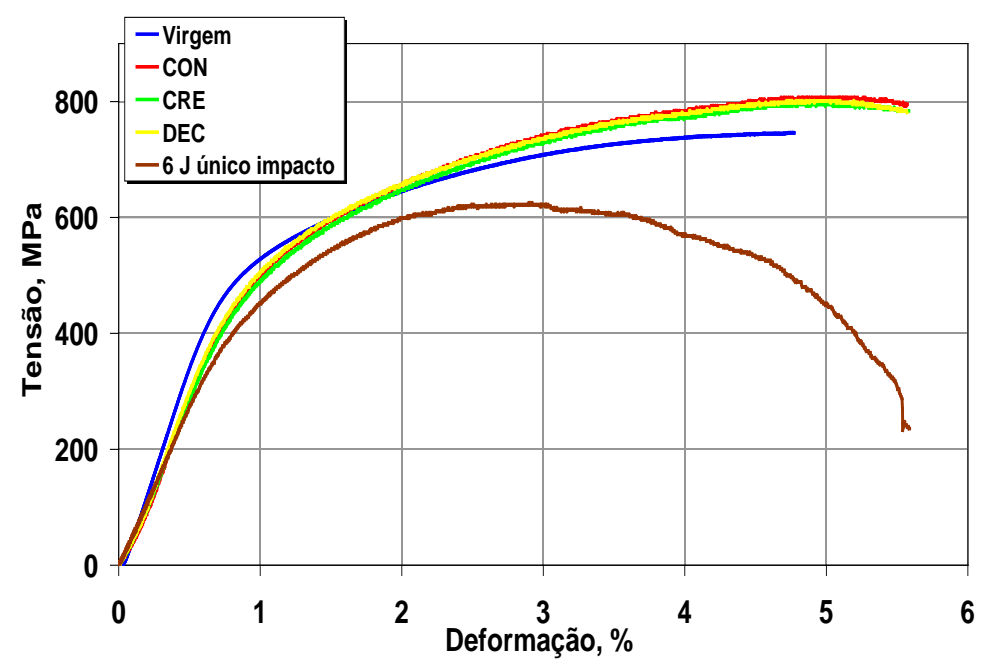

Figura 12: Curvas tensão-deformação (calculadas para o feixe mais externo do CDP submetido ao máximo esforço trativo) dos laminados impactados de modo repetido até uma energia total acumulada de $6 \mathrm{~J}$ (CON, CRE e DEC), comparadas a do mesmo material submetido a impacto único de $6 \mathrm{~J}$, e ao material no estado virgem.

Observa-se que a resistência máxima residual em flexão do Glare na condição de danificado por um único evento de impacto de $6 \mathrm{~J}$ (barra na cor marrom) é claramente inferior a do material na condição virgem ou como-recebida (cor azul). Entretanto, as resistências residuais dos CDPs submetidos a múltiplos impactos, para uma energia acumulada de impacto também de $6 \mathrm{~J}$, apresentam um comportamento anômalo, indicando a possibilidade de o material ter sido eventualmente reforçado ou fortalecido pelas sequências previamente aplicadas de impacto denominadas, respectivamente, CON (vermelha), CRE (verde) e DEC (amarela). Este comportamento é corroborado pela análise da Figura 12, que fornece as curvas de tensão vs. deformação para o LMF-Glare nas condições em que o material foi avaliado neste estudo, bem como em pesquisa anterior [24].

Nota-se na Figura 12 que os espécimes carregados por impactos múltiplos apresentam curvas substancialmente superiores ao do material virgem praticamente ao longo de toda a região de comportamento não-linear. Por outro lado, o laminado submetido ao carregamento concentrado de $6 \mathrm{~J}$ exibe uma curva de resistência mecânica em flexão significativamente inferior a todas as outras condições de ensaio empregadas.

Este aumento da resistência residual do Glare submetido à fadiga por impacto, relativamente à condição virgem do material, constitui uma resposta contrária à esperada do LMF, já que a sua integridade estrutural é degradada devido aos impactos repetidos.

Especula-se que os resultados de flexão residual após a aplicação dos impactos repetidos tenham sido afetados, em maior ou menor extensão, pela geração da calota hemisférica nos LMF durante os choques mecânicos, a qual alterou significativamente a geometria local dos CDPs. Pode-se, portanto, arguir que o módulo da seção [28] do laminado (um parâmetro eminentemente geométrico) tenha sido incrementado a ponto de mais do que compensar o decréscimo da resistência à flexão devido aos danos introduzidos por múltiplos impactos leves no LMF-Glare, gerando um resultado líquido de incremento da resistência mecânica efetiva (ou aparente) dos CDPs.

Segundo as Figuras 11 e 12, somente para uma energia de impacto único, ou concentrado da ordem de $6 \mathrm{~J}$, o comportamento esperado de perda de resistência do laminado foi estabelecido. Nestas circunstâncias, o balanço entre o comportamento essencialmente material, governado pela integridade estrutural do laminado, e o comportamento intrinsecamente mecânico, ditado pela geometria do CDP, pende para o primeiro termo da Equação. É interessante notar que em um trabalho anterior, os autores [24] observaram idênticos fenômenos durante seu estudo sobre o efeito de impacto único em Glare-5, quando verificaram que, tal como no caso presentemente estudado, a resistência mecânica efetivamente era reduzida somente para impactos da ordem de $6 \mathrm{~J}$ ou mais. Pode-se inferir que, para ambos os tipos de impacto, único ou múltiplo, cuja energia total seja inferior a $6 \mathrm{~J}$, o espécime exibirá o fenômeno de fortalecimento aparente como decorrência de efeitos puramente geométricos induzidos no(s) choque(s) mecânico(s).

Há de se ressaltar, entretanto, que as resistências máximas residuais em flexão obtidas para os laminados Glare impactados repetidamente (Figuras 11 e 12) são praticamente idênticas para as três histórias de carregamento por impacto múltiplo (respectivamente CON, CRE e DEC), o que é plenamente concordante tanto com os resultados de energias absorvida e recuperada apresentados no item 4.1, bem como com as análises de danos externos realizadas no item 4.2. 
Por outro lado, conforme mostra a Figura 13, o módulo de elasticidade (módulo de Young) sob flexão do Glare-5 é uma propriedade mecânica residual que reage do modo mais consistente relativamente aos diferentes níveis de energia de impacto(s) previamente aplicado(s) ao laminado híbrido. De fato, e como esperado com base na perda da integridade do material devido aos danos sempre crescentes criados por impactos repetidos, esta propriedade apresenta uma tendência muito clara e bem definida de decréscimo com a aplicação da carga dinâmica.

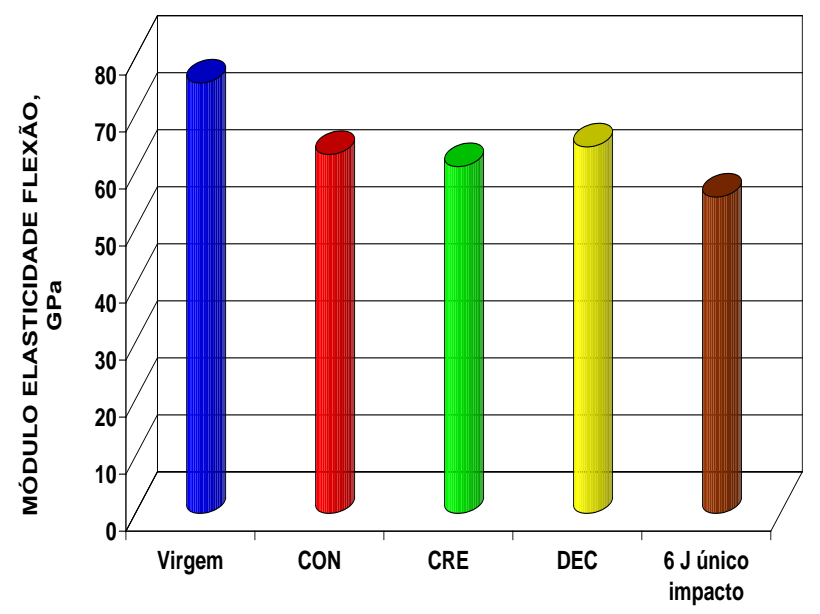

Figura 13: Desempenho do laminado metal/fibra Glare-5 em termos da rigidez em flexão, após diversas condições de impacto repetido (CON, CRE, DEC). A resistência residual do material nas condições virgem e após único impacto de $6 \mathrm{~J}$ [24] são também plotadas para fins de comparação. Valores médios de três ensaios para cada condição avaliada.

Conclui-se da Figura 13 que um provável aumento do módulo da seção do CDP, devido aos impactos sequenciais, foi mais que compensado pela degradação física (i.e. danos criados) experimentada pelo Glare no choque mecânico, de sorte que a rigidez do LMF foi governada pelo último termo da equação, seja para os CDPs submetidos a impactos múltiplos ou a apenas um único impacto. Entretanto, embora seja nítido o decréscimo da rigidez dos espécimes impactados relativamente ao material virgem, e que o impacto concentrado (único) de $6 \mathrm{~J}$ constitui a condição mais crítica de carregamento, dentre os três espécimes submetidos a impactos múltiplos (CON, CRE e DEC), não é possível verificar qualquer diferença nos resultados, o que é concordante com os resultados dos itens 4.1 e 4.2.

Vale ressaltar que, em trabalho prévio [24], ensaiando Glare-5 via impacto único com energias variando entre 1 e $6 \mathrm{~J}$, os autores também concluíram pela maior habilidade do módulo de Young em correlacionar-se quantitativamente com os danos causados no laminado híbrido.

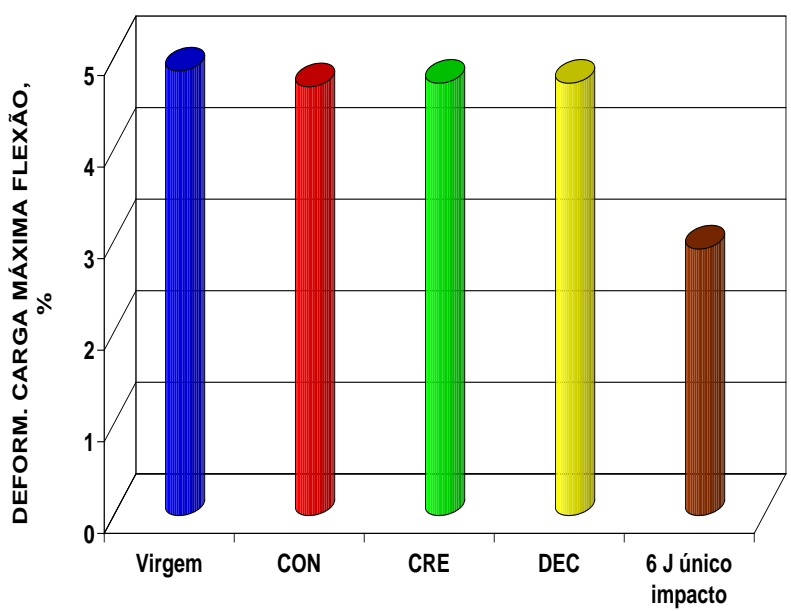

Figura 14: Desempenho do laminado metal/fibra Glare-5 em termos de deformação de carga máxima em flexão, após diversas condições de impacto repetido (CON, CRE, DEC). A resistência residual do material nas condições virgem e após único impacto de $6 \mathrm{~J}$ [24] são também plotadas para fins de comparação.

Valores médios de três ensaios para cada condição avaliada. 
Já os resultados de deformação de carga máxima, plotados na Figura 14, não indicam qualquer alteração desta propriedade residual dos CDPs impactados repetitivamente com relação ao laminado virgem. Por outro lado, o espécime submetido à carga concentrada de $6 \mathrm{~J}$ impingida em um único golpe ao material híbrido mostra uma redução substancial desta propriedade mecânica em flexão três pontos.

Finalmente, a Figura 15 mostra que, assim como a deformação de carga máxima, a tenacidade de carga máxima denuncia nitidamente os danos por impacto somente para o CDP sujeito ao carregamento dinâmico simples (concentrado) com energia de $6 \mathrm{~J}$.

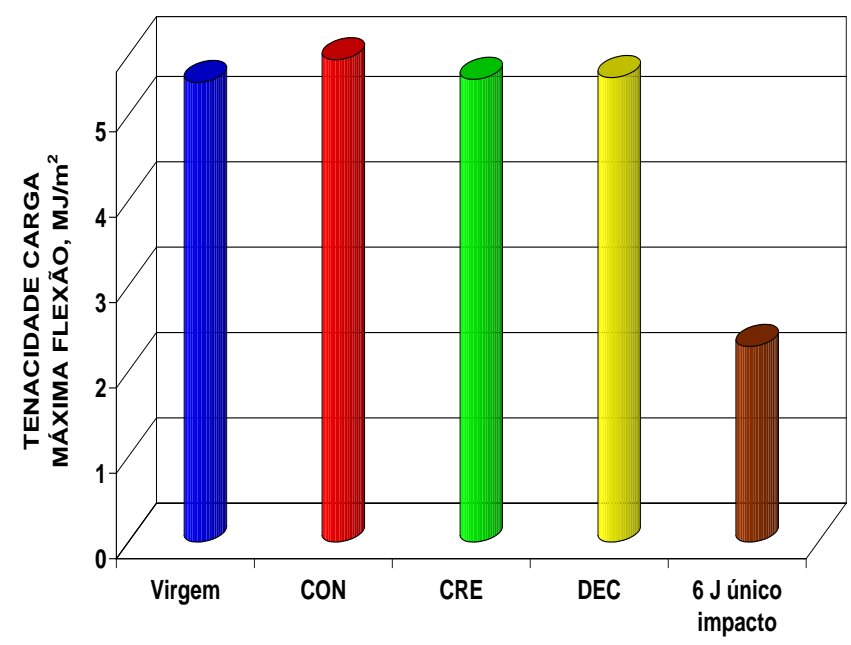

Figura 15: Desempenho do laminado metal/fibra Glare-5 em termos de tenacidade de carga máxima em flexão, após diversas condições de impacto repetido (CON, CRE, DEC). A resistência residual do material nas condições virgem e após único impacto de $6 \mathrm{~J}$ [24] são também plotadas para fins de comparação.

Valores médios de três ensaios para cada condição avaliada.

Os resultados presentemente obtidos, mostrando praticamente idênticos valores de energia absorvida pelo laminado híbrido metal/fibra quando submetido às três distintas histórias de carregamento por impacto repetido, bem como revelando uma extensão de danos externos no material (diâmetro e profundidade das endentações) muito similar nas três condições de ensaio, além de indicando comportamentos mecânicos residuais notavelmente semelhantes para o LMF-Glare após as três sequências de impacto, são concordante com trabalhos anteriores [29-31], nos quais foram desenvolvidas formulações matemáticas correlacionado a resistência residual de laminados compósitos aeronáuticos à profundidade da mossa, bem como à energia de impacto e àquela absorvida pelos materiais durante a aplicação de choques mecânicos.

\section{CONCLUSÕES}

- A energia total absorvida pelos CDPs submetidos à fadiga por impacto é da ordem de $40 \%$ da energia total disponibilizada, independentemente da história de carregamento aplicada (respectivamente energia constante, crescente ou decrescente no intervalo de 0,2 a $1 \mathrm{~J}$ );

- Não foi possível se observarem diferenças visuais entre as mossas (endentações) geradas por impacto no laminado Glare para as distintas histórias de impacto múltiplo, para uma mesma energia acumulada de $6 \mathrm{~J}$. Este fato foi plenamente concordante com os praticamente idênticos valores de energia total absorvida pelo Glare- 5 em todos os modos de carregamento (CON, CRE e DEC);

- Ensaios mecânicos de flexão para a determinação das propriedades residuais pós-impactos múltiplos do Glare-5 não permitiram determinar quaisquer diferenças de comportamento resultante das diversas histórias de impacto aplicadas. Desta forma, em conjunção às observações visuais dos danos externamente impingidos por impacto ao Glare-5 e aos valores de energia absorvida pelo laminado nas várias condições de fadiga por impacto, pôde-se concluir cabalmente pela inexistência de efeitos da sequência ou história de carregamento dinâmico por impacto repetido nesta classe de laminado hibrido metal/fibra;

- A aplicação de um único impacto concentrado de $6 \mathrm{~J}$ mostrou-se uma condição muito mais crítica que a aplicação de múltiplos impactos sequenciais para uma mesma energia total acumulada. Isto foi claramente demonstrado tanto em termos de quantificação de danos como de energia 
percentual absorvida pelos laminados danificados e, principalmente, por intermédio de ensaios de flexão para determinação de suas propriedades residuais;

- Em geral, o módulo de elasticidade residual em flexão foi a propriedade mecânica mais sensível à presença de danos previamente introduzidos por impactos no LMF Glare -5, sejam estes aplicados de modo único ou repetido, refletindo, de modo consistente e inequívoco, a perda de integridade do material como decorrência dos danos impingidos por choque(s) mecânico(s).

\section{AGRADECIMENTOS}

À Aviation Equipments (CA-EUA) pelo suprimento do LMF-Glare-5, à Embraer S/A pela usinagem e preparo dos CDPs, ao Prof. W.J. Cantwell da Universidade de Liverpool (UK) por prover todas as facilidades para os ensaios de impacto, e aos Professores D. Spinelli e W. W. Bose da Escola de Engenharia de São Carlos por disponibilizarem os equipamentos para os ensaios de resistência mecânica residual.

\section{BIBLIOGRAFIA}

[1] VOGELESANG L.B., VLOT A., "Development of fiber-metal laminates for advanced aerospace structures”, Journal Materials Processing \& Technology, v. 103, n. 1, pp.1-5, June, 2000.

[2] VLOT, A., KRULL, M., “Impact damage resistance of various fiber metal laminates”, Journal of Physics IV France, Colloque C3, pp.1045-1050, 1997.

[3] GWEON S.Y., BASCOM W.D., "Damage in carbon-fibre composites due to repetitive low-velocity impact loads”, Journal of Materials Science, v. 27, n. 8, pp. 2035-2047, April 1992.

[4] MITTELMAN A., “Low-energy repetitive impact in carbon-epoxy composite”, Journal of Materials Science, v. 27, n. 9, pp. 2458-2462, May 1992.

[5] OFFRINGA A., DAVIES C.R., "Gulfstream V floors: primary aircraft structure in advanced thermoplastics”, Journal of Advanced Materials, v. 27, pp. 2-10, 1996.

[6] TUSCHAK P.A., "Impact fatigue - a new way of looking at the durability of engineering plastics", $D u$ Pont: The Miracles of Science, p. 3.

[7] MORAIS W.A., MONTEIRO S.N., D’ALMEIDA J.R.M., “Evaluation of repeated low energy impact damage in carbon-epoxy composite materials”, Composite Structures, v. 67, pp. 307-315, 2005.

[8] HONG S., LIU D., “On the relationship between impact energy and delamination area”, Experimental Mechanics, v. 29, n. 2, pp. 115-120, June 1989.

[9] TARPANI J.R., ANGELONI M., IEZZI L., CASTRO C.E.G., "Fadiga após múltiplos impactos em laminados carbono-epóxi”, Tecnologia em Metalurgia e Materiais, v. 2, n. 4, pp. 63-70, AbrilJunho, 2006.

[10] LALIBERTÉ J.F., STRAZNICKY P.V., POON C., "Impact damage in fiber metal laminates, part 1: experiment”, AIAA Journal, v. 43, n. 11, pp. 2445-2451, 2005.

[11] ALDERLIESTEN R.C., BENEDICTUS R., "Fiber/metal composite technology for future primary aircraft structures”, In: $48^{\text {th }}$ AIAA/ASME/ASCE/AHS/ASC Structures, Structural Dynamics, and Materials Conference, 23-26 April, Honolulu, Hawaii, Paper 2404, 2007.

[12] WARDLE B.L., LAGACE P.A., "On the use of dent depth as an impact damage metric for thin composite structures”, Journal of Reinforced Plastics \& Composites, v. 16, n. 12, pp. 1093-1100, 1997.

[13] RAJKUMAR G.R., KRISHNA M., MURTHY H.N.N., SHARMA S.C., MAHESH K.R.V., "Effect of low velocity repeated impacts on property degradation of aluminum-glass fiber laminates", International Journal of Engineering Science \& Technology, v. 3, n. 5, pp. 4131-4139, 2011. 
TARPANI, J.R., CARDOSO, F.L.A.; GUALBERTO, A.R.M.; GATTI M.C.A; Revista Matéria, v. 16, n. 2, pp.668 - 682, 2011.

[14] LIU D., "Size effects on impact response of composite laminates", International Journal of Impact Engineering, v. 21, pp. 837-854, 1998.

[15] DOT/FAA/AR-03/75 - U.S. Department of Transportation, Federal Aviation Administration, Office of Aviation Research and Development, "Tolerance of composite sandwich panels - scaling effects", Final Report, Washington, D.C. 20591, 2004.

[16] DOT/FAA/AR-03/37 - U.S. Department of Transportation, Federal Aviation Administration, Office of Aviation Research and Development, “Advanced aircraft materials - engine debris penetration testing”, Final Report, Washington, D.C. 20591, 2005.

[17] CARRILLO J.G., CANTWELL W.J., "Scaling effects in the low velocity impact response of fiber-metal laminates”, Journal of Reinforced Plastics and Composites, v. 27, pp. 893-907, 2008.

[18] McKOWN S., CANTWELL W.J., JONES N., "Investigation of scaling effects in fiber-metal laminates”, Journal of Composite Materials, v. 42, pp. 865-888, 2008.

[19] MITREVSKI T., "Low-velocity impacts on preloaded GFRP specimens with various impactor shapes”, Composite Structures, v. 76, pp. 209-217, 2006.

[20] MITREVSKI T., "The influence of impactor shape on the damage to composite laminates", Composite Structures, v. 76, pp. 116-122, 2006.

[21] MITREVSKI T., "The effect of impactor shape on the impact response of composite laminates", Composite Structures, v. 67, pp. 139-148, 2005.

[22] WHITTINGHAM B., "The response of composite structures with pre-stress subject to low velocity impact damage”, Composite Structures, v .66, pp. 685-698, 2004.

[23] CORTÉS P., CANTWELL W.J., “The impact properties of high-temperature fiber-metal laminates”, Journal of Composite Materials, v. 41, pp. 613-632, 2006.

[24] GUALBERTO A.R.M., TARPANI J.R., "Resistência e tolerância a impacto transversal de baixa energia de um laminado híbrido metal/fibra”, Revista Matéria, v. 14, n. 2, pp. 795-813, 2009.

[25] AMERICAN SOCIETY FOR TESTING AND MATERIALS, Designation ASTM-D7264M-07: "Standard test methods for flexural properties of polymer matrix composite materials", ASTM International Handbook, 2007.

[26] SUGUN B.S., RAO R.M.V.G.K., "Low-velocity impact characterization of glass, carbon and kevlar composites using repeated drop tests”, Journal of Reinforced Plastics and Composites, v. 23, n. 15, pp. 1583-1599, 2004.

[27] LIU Y.X., LIAW B.M., "Drop-weight impact of fiber-metal laminates using various indenters”, In: Proceedings of the SEM X International Congress \& Exposition on Experimental and Applied Mechanics, Section 106: Damage Detection III, Paper n .386, Costa Mesa-CA, June, 2004.

[28] GERE J.M., Mechanics of Materials, 7 ed., Toronto, Cengage Learning, 2009.

[29] KOMOROWSKI J.P., SIMPSON D.L., GOULD R.W., “A technique for rapid impact damage detection with implication for composite aircraft structures”, Composites, v. 21, n. 2, pp. 169-173, 1990.

[30] KOMOROWSKI J.P., SIMPSON D.L., GOULD R.W., "Enhanced visual technique for rapid inspection of aircraft structures”, Materials Evaluation, v. 49, n. 12, pp. 1486-1490, 1991.

[31] CAPRINO G., LOPRESTO V., "The significance of indentation in the inspection of carbon fibrereinforced plastic panels damaged by low-velocity impact”, Composite Science and Technology, v. 60, pp. 1003-1012, 2000. 